\title{
Interactive comment on "Vertical profiles of sub-micron aerosol single scattering albedo over Indian region immediately before monsoon onset and during its development: Research from the SWAAMI field campaign" by Mohanan R. Manoj et al.
}

\section{Anonymous Referee \#1}

Received and published: 24 September 2019

The authors present single scattering albedo (SSA) profiles obtained over the Indian region during the SWAAMI field campaign in June and July of 2016 . Two profiles are presented from during the Indian monsoon in addition to several profiles sampled before the onset of the monsoon. The SSA measurements are derived from measurements for absorption coefficient made by the Particle Soot Absorption Photometer (PSAP) and scattering coefficient made by TSI-3563 nephelometer. Significant variation in the SSA was observed during the campaign, with values ranging from near unity

Printer-friendly version

Discussion paper 
to as low as 0.7 in one region. All profiles are explored through back trajectory, radiative forcing (RF) and heating rate calculations. The temporal, horizontal and vertical variations in SSA was attributed primarily to the prevailing wind patterns, with the most absorbing particles being advected from the Middle East, a finding consistent with previous studies (e.g. Moorthy et al., 2007). It was found that the vertical profile of SSA can have a non-negligible impact of top-of-atmosphere (TOA) radiative forcing values and that higher optical thickness and stronger absorption both correlated with larger heating rates.

Aerosol-monsoon interactions over South Asia is a very active research topic for which many open questions remain. Some key details are omitted from the manuscript but, overall, the present work appears to be a scientifically sound exploration of this topic. However, only six different profiles are presented, and only one pair of these consists of measurements made before and during the monsoon at the same location. Many other studies have explored monsoon-aerosol interactions over India using aircraft data (see Li et al., 2016 ) —including an analysis of measurements from the same period as the present manuscript (Vaishya et al., 2018)_and it is not clear to me what makes the data presented in the present work particularly unique. Moreover, the supporting RF and heating rate calculations that are provided do not seem to generate novel insights. The fact that increased quantities of absorbing aerosol leads to higher heating rates is well established (e.g. Ramanathan et al., 2007). The potentially meaningful dependence of radiative forcing on the vertical profile of SSA, elucidated by the simulations, is less self-evident but has been discussed extensively elsewhere (e.g. Haywood et al., 1998; Meloni et al., 2005; Guan et al., 2010). In my opinion, the manuscript may be technically sound but the overall conclusions are not substantial enough to merit publication in high impact journal like ACP.

Printer-friendly version

Moorthy, K.K., Babu, S.S., Satheesh, S.K., Srinivasan, J. and Dutt, C.B.S., 2007. Dust absorption over the "Great Indian Desert" inferred using groundâĂ ̌̌based and satellite remote sensing. Journal of Geophysical Research: Atmospheres, 112(D9). 
Li, Z., Lau, W.M., Ramanathan, V., Wu, G., Ding, Y., Manoj, M.G., Liu, J., Qian, Y., Li, J., Zhou, T. and Fan, J., 2016. Aerosol and monsoon climate interactions over Asia. Reviews of Geophysics, 54(4), pp.866-929.

Kulkarni, J.R., Maheskumar, R.S., Morwal, S.B., Padmakumari, B., Konwar, M., Deshpande, C.G., Joshi, R.R., Bhalwankar, R.V., Pandithurai, G., Safai, P.D. and Narkhedkar, S.G., 2012. The cloud aerosol interactions and precipitation enhancement experiment (CAIPEEX): overview and preliminary results. Curr. Sci, 102(3), pp.413-425.

Vaishya, A., Babu, S.N.S., Jayachandran, V., Gogoi, M.M., Lakshmi, N.B., Moorthy, K.K. and Satheesh, S.K., 2018. Large contrast in the vertical distribution of aerosol optical properties and radiative effects across the Indo-Gangetic Plain during the SWAAMI-RAWEX campaign. Atmospheric Chemistry and Physics, 18(23), pp.1766917685.

Ramanathan, V., Ramana, M.V., Roberts, G., Kim, D., Corrigan, C., Chung, C. and Winker, D., 2007. Warming trends in Asia amplified by brown cloud solar absorption. Nature, 448(7153), p.575.

Meloni, D., Di Sarra, A., Di lorio, T. and Fiocco, G., 2005. Influence of the vertical profile of Saharan dust on the visible direct radiative forcing. Journal of Quantitative Spectroscopy and Radiative Transfer, 93(4), pp.397-413.

Haywood, J.M. and Ramaswamy, V., 1998. Global sensitivity studies of the direct radiative forcing due to anthropogenic sulfate and black carbon aerosols. Journal of Geophysical Research: Atmospheres, 103(D6), pp.6043-6058.

Guan, H., Schmid, B., Bucholtz, A. and Bergstrom, R., 2010. Sensitivity of shortwave radiative flux density, forcing, and heating rate to the aerosol vertical profile. Journal of Geophysical Research: Atmospheres, 115(D6).

Interactive comment on Atmos. Chem. Phys. Discuss., https://doi.org/10.5194/acp-2019-657, 2019. 